\title{
Chemical Coding for Cardiovascular Sympathetic Preganglionic Neurons in Rats
}

\author{
David G. Gonsalvez, ${ }^{1}$ Ilan A. Kerman, ${ }^{2}$ Robin M. McAllen, ${ }^{3}$ and Colin R. Anderson ${ }^{1}$ \\ ${ }^{1}$ Department of Anatomy and Cell Biology, University of Melbourne, Melbourne 3010, Victoria, Australia, ${ }^{2}$ Molecular and Behavioral Neuroscience \\ Institute, University of Michigan, Ann Arbor, Michigan 48109-0720, and ${ }^{3}$ Howard Florey Institute of Experimental Physiology, Melbourne 3010, Victoria, \\ Australia
}

Cocaine and amphetamine-regulated transcript peptide (CART) is present in a subset of sympathetic preganglionic neurons in the rat. We examined the distribution of CART-immunoreactive terminals in rat stellate and superior cervical ganglia and adrenal gland and found that they surround neuropeptide Y-immunoreactive postganglionic neurons and noradrenergic chromaffin cells. The targets of CARTimmunoreactive preganglionic neurons in the stellate and superior cervical ganglia were shown to be vasoconstrictor neurons supplying muscle and skin and cardiac-projecting postganglionic neurons: they did not target non-vasoconstrictor neurons innervating salivary glands, piloerector muscle, brown fat, or adrenergic chromaffin cells. Transneuronal tracing using pseudorabies virus demonstrated that many, but not all, preganglionic neurons in the vasoconstrictor pathway to forelimb skeletal muscle were CART immunoreactive. Similarly, analysis with the confocal microscope confirmed that $70 \%$ of boutons in contact with vasoconstrictor ganglion cells contained CART, whereas 30\% did not. Finally, we show that CART-immunoreactive cells represented $69 \%$ of the preganglionic neuron population expressing c-Fos after systemic hypoxia. We conclude that CART is present in most, although not all, cardiovascular preganglionic neurons but not thoracic preganglionic neurons with non-cardiovascular targets. We suggest that CART immunoreactivity may identify the postulated "accessory" preganglionic neurons, whose actions may amplify vasomotor ganglionic transmission.

\section{Introduction}

Functional groups of neurons can often be defined by the distinctive combinations of substances they express. The tight correlation of chemical phenotype and function (sometimes called chemical coding) is often exploited to identify neurons of specific function in both the CNS and peripheral nervous systems e.g., retina (Marc and Jones, 2002), cortical interneurons (Markram et al., 2004), and enteric nervous system (Furness, 2006). In the peripheral parts of the autonomic nervous system, the relationship between chemical code and function may be set by target-derived signals (Landis, 1992; Cane and Anderson, 2009), and the result defines separate pathways formed from preganglionic and postganglionic neurons linking the CNS to a wide range of peripheral effector tissues (Macrae et al., 1986; Benarroch, 1994; Gibbins, 1995; Grkovic and Anderson, 1997; Cane and Anderson, 2009). Similarly, targetspecific pathways can be identified electrophysiologically by their different patterns of reflex activation (Jänig, 2006).

Examples of specific chemical codes defining the final sympathetic motor pathway in the rat include motor pathways to the

Received Feb. 12, 2010; revised July 4, 2010; accepted July 14, 2010.

I.A.K. was supported by National Institutes of Health (NIH) Grant 5K99MH081927-02 and a National Alliance for Research on Schizophrenia and Depression Young Investigator Award. Pseudorabies virus strains used in this work were provided by Lynn Enquist (Department of Molecular Biology and Princeton Neuroscience Institute, Princeton University, Princeton, NJ), who acknowledges funding from NIH Grants P40 RR 018604 and R37 NS 033506 . We acknowledge the expert technical assistance of Jan Morgan and Dr. Peter Howe for the kind gift of PNMT antiserum.

Correspondence should be addressed to Dr. Colin R. Anderson, Department of Anatomy and Cell Biology, The University of Melbourne, Melbourne 3010, VIC, Australia. E-mail: c.anderson@unimelb.edu.au.

DOI:10.1523/JNEUROSCI.0796-10.2010

Copyright $\odot 2010$ the authors $\quad 0270-6474 / 10 / 3011781-11 \$ 15.00 / 0$ heart, in which postganglionic neurons contain neuropeptide $\mathrm{Y}$ (NPY) and calbindin (Richardson et al., 2006) and the preganglionic neurons contain calretinin, and motor pathways to the iris, in which the postganglionic neurons contain NPY and calbindin and the preganglionic neurons contain calcitonin gene-related peptide (Grkovic et al., 1999). However, one notable absence is a chemical code that identifies preganglionic neurons of the largest and most important functional group: vasoconstrictor neurons. In the rat, vasoconstrictor postganglionic neurons contain NPY, but to date no identifying chemical phenotype is known for the preganglionic neurons that control them.

In some ganglionic pathways, peptides may be coreleased with acetylcholine, especially on high-frequency preganglionic stimulation (Bachoo et al., 1987). In vasomotor pathways, no such peptide has yet been identified, but it has been sought to account for two findings: (1) ganglionic transmission that survives ganglionic blockade with both hexamethonium and atropine (Jänig et al., 1982, 1984), and (2) potentiation of ongoing ganglionic transmission for tens of minutes after stimulation of a cut white ramus (Blumberg and Janig, 1983). Peptidergic actions were inferred (Jänig, 2006). In both cases, the action was specific to vasoconstrictor pathways (muscle, cutaneous) and did not affect non-cardiovascular pathways (pilomotor, sudomotor) (Blumberg and Janig, 1983; Jänig et al., 1984). Intriguingly, these putative peptidergic actions may be driven by central and preganglionic pathways that are functionally distinct from those carrying most ongoing vasomotor tone (Henderson and Ungar, 1978; Janig et al., 1983; Jänig, 2006). Elucidation of this matter would be greatly helped by identification of the candidate peptide. 
The neuropeptide cocaine and amphetamine-regulated transcript (CART) has been identified in a proportion of rat sympathetic preganglionic neurons (SPNs) (Dun et al., 2000; Fenwick et al., 2006). CART is widely distributed among neurons of the CNS (Koylu et al., 1998) and has been implicated in the central regulation of feeding (Thim et al., 1998). Although Fenwick et al. (2006) formed the view that the preganglionic neurons labeled by CART crossed the boundaries of functional class, we have reinvestigated the possibility that CART selectively labels preganglionic neurons supplying cardiovascular targets (cardiac, vasoconstrictor, and noradrenergic adrenal). Additional studies have addressed the question of how comprehensive and how exclusive might that innervation by CART-containing preganglionic neurons be.

\section{Materials and Methods}

Animals. Sprague Dawley rats of either sex and of 180-300 g were used in the following experiments. All experiments were approved by the Animal Ethics and Experimentation Committee of the University of Melbourne and University of Michigan as appropriate and conformed to the Society for Neuroscience Policy on the Use of Animals in Neuroscience Research.

Retrograde labeling of postganglionic neurons with Fast Blue. For the following procedures, animals were anesthetized with a mixture of ketamine and xylazine (60 and $10 \mathrm{mg} / \mathrm{kg}$, respectively, i.m.). For the retrograde tracer Fast Blue, injections of a $2 \%$ solution in 10\% dimethylsulfoxide in distilled water (Sigma) were made into one of seven sites (iris, forehead or forelimb skin, submandibular salivary gland, masseter or triceps muscle, or the interscapular brown fat) using a glass micropipette. Iris injections were made into the anterior chamber of the eye through a 30 gauge needle hole made at the margin of the cornea: approximately $300 \mathrm{nl}$ of Fast Blue solution was injected. Skin injections were made into a 30 gauge needle hole made intradermally, parallel to the skin surface: two to four separate injections of $\sim 300 \mathrm{nl}$ were made for each animal. Masseter and forelimb muscle injections were made directly into the muscle through a $2 \mathrm{~mm}$ skin incision: two $300 \mathrm{nl}$ injections were made in each case. The wound was closed with cyanoacrylate glue. The subscapular brown fat was exposed with a midline incision in the skin between the shoulder blades: two or three lobes of brown fat were each injected with a single $300 \mathrm{nl}$ injection of Fast Blue. A minimum of three animals were investigated for each target, and survival times were between 4 and $7 \mathrm{~d}$.

Anterograde labeling of sympathetic preganglionic neuron with intraspinal injections of biotinylated dextran. Rats $(n=6)$ were anesthetized with ketamine and xylazine (see above), and a midline incision made in the skin between the shoulder blades. The muscle over the upper thoracic cord was divided in the midline and the longest neural spine identified as $\mathrm{T} 2$. The trailing edge of the $\mathrm{T} 2$ vertebrae was removed to expose a small area of the thoracic spinal cord. The dura was punctured with a 30 gauge needle, and a glass micropipette mounted vertically in a micromanipulator was lowered vertically into the spinal cord $1 \mathrm{~mm}$ lateral to the midline and $1 \mathrm{~mm}$ deep, and a single $200 \mathrm{nl}$ injection of 10,000 molecular weight dextran (15\% in distilled water; Invitrogen) was made. The micropipette was left in place for $1 \mathrm{~min}$ to prevent leakage and then slowly removed. Muscle and skin were sutured separately, and the animals were allowed to recover. Survival times were 5-7 d.

Virally mediated transneuronal tracing. Preganglionic neurons projecting to postganglionic neurons supplying the rat triceps muscle were labeled transneuronally with pseudorabies virus (PRV). Adult Sprague Dawley rats (Charles River) weighing $332.8 \pm 12.4$ g (303-361 g) were injected with PRV-152, a green fluorescent protein (GFP)-expressing PRV strain engineered from PRV-Bartha (Billig et al., 2000). Injections were performed using an approach validated previously in the gastrocnemius muscle (Kerman et al., 2003, 2006). Briefly, animals were anesthetized with $5 \%$ isoflurane in $\mathrm{O}_{2}$ and were injected with 20 or $30 \mu \mathrm{l}$ of PRV-152 $\left(10^{8}-10^{9} \mathrm{pfu} / \mathrm{ml}\right)$ into the left triceps muscle. PRV-152 was pressure injected via a small-diameter glass pipette attached to a Hamilton syringe (Hamilton Company) into multiple sites ( $1.0 \mu \mathrm{l} / \mathrm{site})$, which were evenly distributed between the long and lateral heads of the triceps. To minimize nonspecific viral spread, the pipette was left in place for $30-60 \mathrm{~s}$ after each injection, and the muscle was swabbed with cottontipped applicators and surgical gauze. Incisions were closed with surgical sutures, and animals were returned to their home cages and allowed to survive to $48(n=2), 60(n=1), 72(n=1)$, or $84 \mathrm{~h}(n=1)$. At the appropriate survival times, animals were deeply anesthetized with Nembutal $(150 \mathrm{mg} / \mathrm{kg}$, i.p.) and transcardially perfused with physiological saline, followed by Zamboni's fixative.

Induction of c-Fos expression with hypoxia. Animals were injected intraperitoneally with $1 \mathrm{mg} / \mathrm{ml}$ Fluorogold dissolved in $500 \mu \mathrm{l}$ of distilled water to retrogradely label all SPNs (Anderson and Edwards, 1994). Five to $7 \mathrm{~d}$ later, they were subjected to $90 \mathrm{~min}$ exposure to $8 \%$ oxygen, by delivering a mixture of nitrogen and air into a transparent canopy placed over the animal's home cage. The hypoxic gas was removed, and animals breathed room air for an additional 30 min before being deeply anesthetized (pentobarbitone, $100 \mathrm{mg} / \mathrm{kg}$, i.p.) for perfusion fixation.

Perfusion and sectioning. Anesthetized animals were perfused via the ascending aorta with $300-500 \mathrm{ml}$ of Zamboni's fixative (2\% formaldehyde, $1.8 \%$ picric acid in $0.1 \mathrm{~m}$ phosphate buffer). Superior cervical ganglia (SCG), stellate ganglia, and spinal cord were removed as required, postfixed for $2 \mathrm{~h}$ in the same fixative, and washed three times for $5 \mathrm{~min}$ in PBS (in mM: $145 \mathrm{NaCl}, 7.5 \mathrm{Na}_{2} \mathrm{PO}_{4}$, and $2.5 \mathrm{NaH}_{2} \mathrm{PO}_{4} \cdot \mathrm{H}_{2}$ ). In addition, three rats that did not have Fast Blue or virus injections were anesthetized with pentobarbitone and perfused as above, and the adrenal glands were removed for analysis.

Sectioning and immunohistochemistry. After cryoprotecting in 15\% sucrose overnight, ganglia and adrenals were snap frozen in liquidnitrogen-cooled isopentane, sectioned at $14 \mu \mathrm{m}$ on a cryostat, and dried onto $1 \%$ gelatin-coated slides. Ganglia from animals injected with dextran intraspinally were treated identically except that they were sectioned at $25 \mu \mathrm{m}$ and collected free floating in PBS. Spinal cords were cut at segmental boundaries (the most caudal dorsal rootlet for each segment), the meninges were removed, and each segment was sectioned horizontally on a Vibratome at a thickness of $50 \mu \mathrm{m}$. Sections were collected free floating in PBS. Both free-floating sections and slides were stained with mixtures of primary antibodies (Table 1) for multiple-label immunofluorescence. References establishing the source and specificity of the antisera are included in Table 1 except for the following. Monoclonal mouse anti-CART was raised against recombinant human CART 1-89. The manufacturer reports that the antibody detects recombinant human CART in direct ELISAs and Western blots and can also detect recombinant human CART 42-89. In our hands, it produced identical patterns of staining to the rabbit anti-rat CART also used in this study.

Goat anti-GFP was raised against purified GFP from Aequorea victoria. The pattern of staining (only ipsilateral to GFP-expressing pseudorabies virus injections and absent in animals not injected with GFP virus) confirms that it does not recognize any antigen endogenous to the rat.

Antibodies were made up in diluent consisting of PBS containing $0.5 \%$ Triton X-100 and $0.1 \%$ sodium azide and applied for $24-48 \mathrm{~h}$. Secondary antibodies (Table 1) were applied for $1-2 \mathrm{~h}$ in the same diluent. Sections were mounted in Dako Fluorescent Mounting Medium.

Imaging and analysis. Some sections were examined and imaged using a Carl Zeiss Axioskop fluorescence microscope fitted with filters to view Alexa Fluor 488, Alexa Fluor 594, Fast Blue/7-amino-4-methylcoumarin-3-acetic acid (AMCA), and Alexa Fluor 647 and a Carl Zeiss Axiocam Mrm digital camera and Axiovision 4.6 software. The rest of the sections were examined and imaged using a Carl Zeiss 510 Meta scanning confocal microscope fitted with 405, 488, 561, and $633 \mathrm{~nm}$ laser and Carl Zeiss LSM software. All images were adjusted (global contrast and brightness adjustments only) and measured using Carl Zeiss LSM Image Browser version 4.0.0.241 or NIH Image version 1.42q software. All analysis was performed on neurons in which the nucleus was clearly outlined in images taken with a $40 \times$ or $63 \times$ objective lens.

The density of innervation (the "innervation score") of individual postganglionic neurons by preganglionic terminals was determined using NIH ImageJ software on single confocal images of neuronal profiles. The polygon tool in NIH ImageJ was used to outline the profile of the cell. The enlarge command was then used to expand the outline radially by 3 
Table 1. Antisera and immunohistochemical reagents used

\begin{tabular}{|c|c|c|c|c|}
\hline Antiserum & Catalog\# & Species & Source and characterization & References \\
\hline \multicolumn{5}{|l|}{ Primary } \\
\hline Calbindin D28 & Ab1778, lot 22120130 & Rabbit & Millipore Bioscience Research Reagents & Kim et al., 2006 \\
\hline CART & H-003-62, lot 01033 & Rabbit & Phoenix Pharmaceuticals & Dun et al., 2000 \\
\hline CART & MAB163, clone 113612, lot Esx01 & Mouse & R \& D Systems & \\
\hline ChAT & AB144P & Goat & Millipore Corporation & Corcoran et al., 2004; Horn et al., 2008 \\
\hline c-Fos & SC-52-G, lot D2506 & Goat & Santa Cruz Biotechnology & Tse et al., 2008 \\
\hline GFP & 600-101-215, lot 11680 & Goat & Rockland & \\
\hline Neuropeptide $Y$ & $A B 1583$, lot 22070902 & Sheep & Millipore Bioscience Research Reagents & Blessing et al., 1986 \\
\hline PNMT & $\mathrm{J} 3-7$ & Sheep & Anderson and Howe, 1988 & \\
\hline Synaptophysin & M 0776, lot 087 & Mouse & Dako & Wiedenmann and Franke, 1985; Knaus and Betz, 1990 \\
\hline \multicolumn{5}{|l|}{ Secondary } \\
\hline Goat lgG, Alexa 594 & A11058, lot 440446 & Donkey & Invitrogen & \\
\hline Mouse lgG, Alexa 647 & A31571, lot 423849 & Donkey & Invitrogen & \\
\hline Mouse lgG, Texas Red & $705-075-147$, lot 72020 & Donkey & Jackson ImmunoResearch & \\
\hline Mouse lgG, Alexa 647 & A31571, lot 423849 & Donkey & Invitrogen & \\
\hline Rabbit IgG, FITC & 711-095-152, lot 74737 & Donkey & Jackson ImmunoResearch & \\
\hline Sheep IgG, AMCA & T413-155-003, lot 23972 & Donkey & Jackson ImmunoResearch & \\
\hline \multicolumn{5}{|l|}{ Streptavidin conjugates } \\
\hline Streptavidin-Alexa Fluor 594 & S-11227, Lot 65B2-1 & & Invitrogen & \\
\hline
\end{tabular}

$\mu \mathrm{m}$ so as to encompass the region containing any CART-IR terminals around the cell. The image of the CART-IR terminals was thresholded to select all immunoreactive (IR) terminals, and the area of highlighted terminals within the expanded cell profile was calculated and expressed as a percentage of the $3 \mu \mathrm{m}$ area bordering the cell.

Optical sections from confocal $z$-series through pericellular baskets of CART-IR terminals around Fast Blue-labeled neurons both with and without NPY immunoreactivity were analyzed for the expression of CART, synaptophysin, and, when appropriate, dextran. Initially, individual confocal images were selected from each $z$-series. The profile of the postganglionic neuron was drawn, using NIH ImageJ (version 1.38x), based on the Fast Blue channel, the NPY status of the cell was determined, and any synaptophysin and CART-IR boutons in contact with the cell surface were counted and scored for overlap. When dextran-labeled terminals were to be analyzed in addition to those immunoreactive for CART and synaptophysin, a slightly different procedure was followed. No Fast Blue labeling was used. NPY-IR neurons only were analyzed, and the NPY channel was used to draw the outline of the cell profile. Analysis was made only of synaptophysin-containing boutons apparently in contact with the surface of the NPY-IR neurons. A mask of the synaptophysin-IR boutons was created (in NIH Image J) by thresholding and conversion of the result to a binary image. The mask of the synaptophysin boutons was inverted and subtracted from both the CART and dextran channels. By this means, only synaptophysin-IR boutons were analyzed for CART coexpression with dextran labeling.

Counts of SPNs labeled with immunoreactivity to CART and GFP or CART immunoreactivity and c-Fos were made using the fluorescence microscope. For each segment, all sections through the intermediate zone were analyzed. In animals retrogradely labeled with virus, all profiles of SPNs expressing GFP and containing a nucleus were counted, and the number showing immunoreactivity to CART was recorded. For each cell, its area and the distance of the center of the cell from the lateral margin of the gray matter was measured. The size and relative location of virus-labeled preganglionic neurons were compared using unpaired $t$ tests. For studies on c-Fos expression by SPNs after hypoxia, all nucleated profiles of SPNs labeled after intraperitoneally delivered Fluorogold were counted and scored for CART and/or c-Fos immunoreactivity.

\section{Results}

\section{Does CART immunoreactivity label preganglionic} vasoconstrictor neurons?

CART-immunoreactive terminals were present in both the stellate ganglia and SCG, forming dense pericellular baskets of varicose terminals around many, but not all, postganglionic neurons (Fig. 1A). Immunoreactivity for NPY is present in vasoconstric- tor ganglion cells in rats (Cannon et al., 1986; Edvinsson et al., 1987; Pernow et al., 1987; Lacroix et al., 1990; Schotzinger and Landis, 1990; Grkovic and Anderson, 1995; Ekström et al., 1996; Grkovic and Anderson, 1997). Sections were therefore costained with antisera to NPY and CART. Approximately half of all postganglionic neurons in both the SCG and stellate ganglia were immunoreactive for NPY, and CART-IR terminals were almost exclusively associated with NPY-IR cells (Fig. $1 A-C$ ).

This association was quantified by two approaches. First, 50 postganglionic neurons with and 50 without NPY immunoreactivity were selected at random in the stellate or superior cervical ganglion while the observer was blind to the pattern of CART immunoreactivity. CART immunoreactivity was then revealed, and the innervation of each cell by CART-IR pericellular baskets was scored as described in Materials and Methods. In the stellate ganglia, postganglionic neurons with NPY had an innervation score of $11.0 \pm 1.11$, whereas postganglionic neurons without NPY had a significantly lower score of $3.7 \pm 0.48$ (unpaired $t$ test, $t=5.98$, df $=98, p \ll 0.001)$. In the SCG, the mean innervation score of NPY neurons $(6.5 \pm 0.76)$ was also significantly larger than that of non-NPY neurons $(0.98 \pm 0.27$, unpaired $t$ test, $t=$ $6.90, p \ll 0.001)$. Second, the 50 densest CART-IR pericellular baskets were selected from images of either the stellate or superior cervical ganglion by an observer blind to the pattern of NPY staining. In this case, 90 and $98 \%$, respectively, of the baskets surrounded NPY-IR cells.

An additional proof that rat vasoconstrictor neurons express CART immunoreactivity was sought by transneuronal viral labeling from skeletal muscle, a target that receives purely vasoconstrictor postganglionic neurons (Häbler et al., 1994). The modified pseudorabies virus PRV-152 carries the gene for enhanced green fluorescent protein (EGFP) and was injected into the triceps muscle on one side of five rats. Animals were allowed to survive $48 \mathrm{~h}(n=2), 60 \mathrm{~h}, 72 \mathrm{~h}$, and $84 \mathrm{~h}(n=1$ each) before perfusion-fixation. EGFP-labeled preganglionic neurons were present ipsilateral to the injection in the thoracic spinal cord of all animals (Fig. $1 D-F$ ), and their numbers increased with survival time. CART-IR preganglionic neurons were also present in the spinal cord in all cases, but their numbers decreased with survival time, and this occurred selectively on the side injected with virus. Evidently, the presence of virus in preganglionic neurons pro- 
gressively downregulated the expression of CART immunoreactivity: to minimize this factor, only the two animals given $48 \mathrm{~h}$ survival time were therefore analyzed in detail.

A total of 215 virus-labeled preganglionic neurons were analyzed in the two animals ( 172 and 43, respectively). Of these, $73 \%$ were immunoreactive for CART. Virus-labeled cells with CART immunoreactivity did not differ from those without CART immunoreactivity in either cross-sectional area $(326 \pm 128$ vs $401 \pm$ $304 \mu \mathrm{m}^{2}$, respectively; unpaired $t$ test, $p=$ 0.07 ) or mean distance from edge of white matter $(55.4 \pm 38.2$ vs $54.1 \pm 30.9 \mu \mathrm{m}$, respectively; unpaired $t$ test, $p=0.8$ ).

\section{Does CART immunoreactivity mark preganglionic cardiovascular neurons selectively?}

We next investigated the association of CART-IR terminals with postganglionic neurons of different functions. Fast Blue, previously injected into a range of target tissues, was used to label neurons in stellate and superior cervical ganglia with defined projections. Sections of these ganglia were also costained for CART immunoreactivity and NPY immunoreactivity (Fig. 1G-J). The combination of NPY immunoreactivity and retrograde transport from different target tissues was used to identify different populations of sympathetic postganglionic neurons, as previously reported. Briefly, nearly all postganglionic neurons labeled from masseter and forelimb muscle were immunoreactive for NPY and were inferred to be vasoconstrictor in function (Pernow et al., 1987; Grkovic and Anderson, 1997). Retrograde transport of Fast Blue from the skin, submandibular salivary gland, and brown fat labeled neurons with and neurons without NPY immunoreactivity: those with NPY immunoreactivity were classified as vasoconstrictor based on the previously reported distribution and chemistry of sympathetic terminals in these tissues (Cannon et al., 1986; Schotzinger and Landis, 1990; Grkovic and Anderson, 1997). Neurons lacking NPY were variously classified as pilomotor (among skin-projecting cells), secretomotor (among salivary gland-projecting cells), and thermogenic (among brown fatprojecting cells). Neurons retrogradely labeled from the iris were all NPY-IR and were classified as iridomotor (Terenghi et al., 1983; Grkovic et al., 1999). In addition, cardiac-projecting postganglionic neurons were identified by a combination of topography and chemistry. Cardiac-projecting neurons are large cells that lie on the ventromedial edge of the stellate ganglion around the origins of the cardiac nerves, and they express both NPY and the calcium-binding protein calbindin (Richardson et al., 2006). Cells that showed this chemistry and were closer than three cell diameters to the ventromedial edge of the ganglion were selected for analysis as putative cardiac neurons (Fig. $2 A-C$ ). In each case, the density of CART-IR terminals around retrogradely labeled neurons was determined.
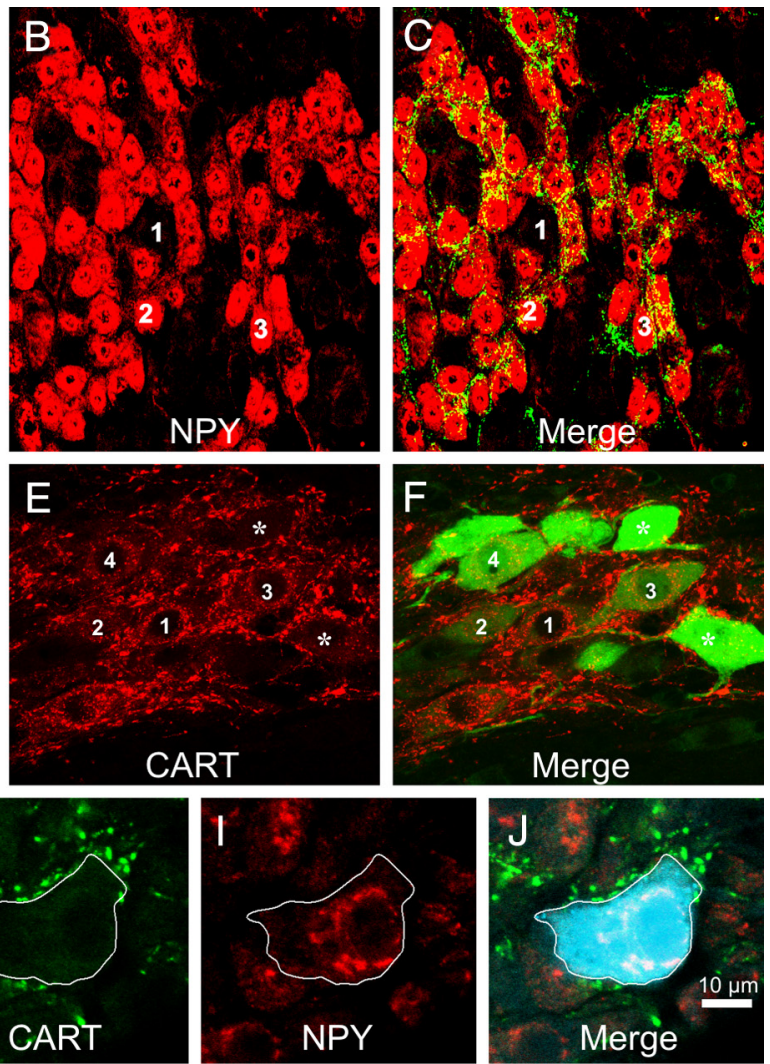

CART

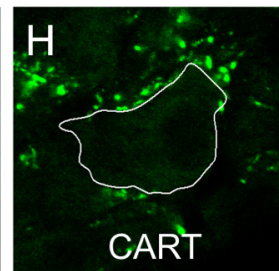

Figure 1. $\boldsymbol{A}-\boldsymbol{C}$, All images are projected $z$-series of confocal images. Rat stellate ganglion stained for immunoreactivity to CART $(\boldsymbol{A})$ and moreactive for NPY. The same cells are labeled 1-3 in each series of image D-F Allimages are projected z-series of confoca

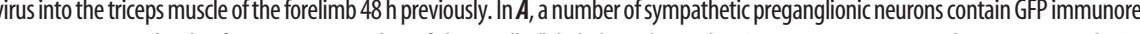
the stellate ganglion labeled from the forelimb muscle with Fast Blue (FB). The Fast Blue-labeled cell $(\boldsymbol{G})$ is also immunoreactive forNPY $(\boldsymbol{H})$ and surrounded by terminals immunoreactive for CART (I).Jshows all images overlaid together. NPY-immunoreactive neurons projecting to skeletal muscle are vasoconstrictor neurons.

We first compared the pooled innervation scores of the cardiovascular neurons (NPY-IR neurons projecting to the forelimb and masseter muscle, salivary gland, brown fat, and skin plus cardiac neurons) with non-cardiovascular neurons (non-NPYimmunoreactive neurons projecting to the skin, brown fat, and salivary glands plus iris-projecting neurons) (Fig. 2E). The innervation score of cardiovascular neurons was fivefold higher than that of non-cardiovascular neurons $(8.5 \pm 0.36$ vs $1.6 \pm 0.26, t=$ $14.2, p \ll 0.001)$.

Consistent with this pattern, the difference between the CART-IR innervation of vascular and non-vascular neurons was maintained when comparisons were made within a pathway going to a single tissue (salivary gland vasculature vs salivary gland secretomotor, brown fat vasculature vs brown fat thermogenic, skin vasomotor vs skin pilomotor) (Fig. $2 F$ ). The vascular targets all had significantly higher innervation scores (unpaired $t$ test, skin vascular vs pilomotor, $t=8.0, \mathrm{df}=98, p \ll 0.001$; brown fat vascular vs non-vascular, $t=4.1, \mathrm{df}=98, p<0.001$; salivary gland vascular vs non-vascular, $t=3.5$, $\mathrm{df}=98, p \ll 0.001)$. Postganglionic neurons going to forelimb or masseter muscle (purely vascular targets) and the heart also had high innervation scores by CART-IR neurons, whereas neurons supplying the iris muscle (a non-vascular target) had very low scores (Fig. $2 \mathrm{~F}$ ). 

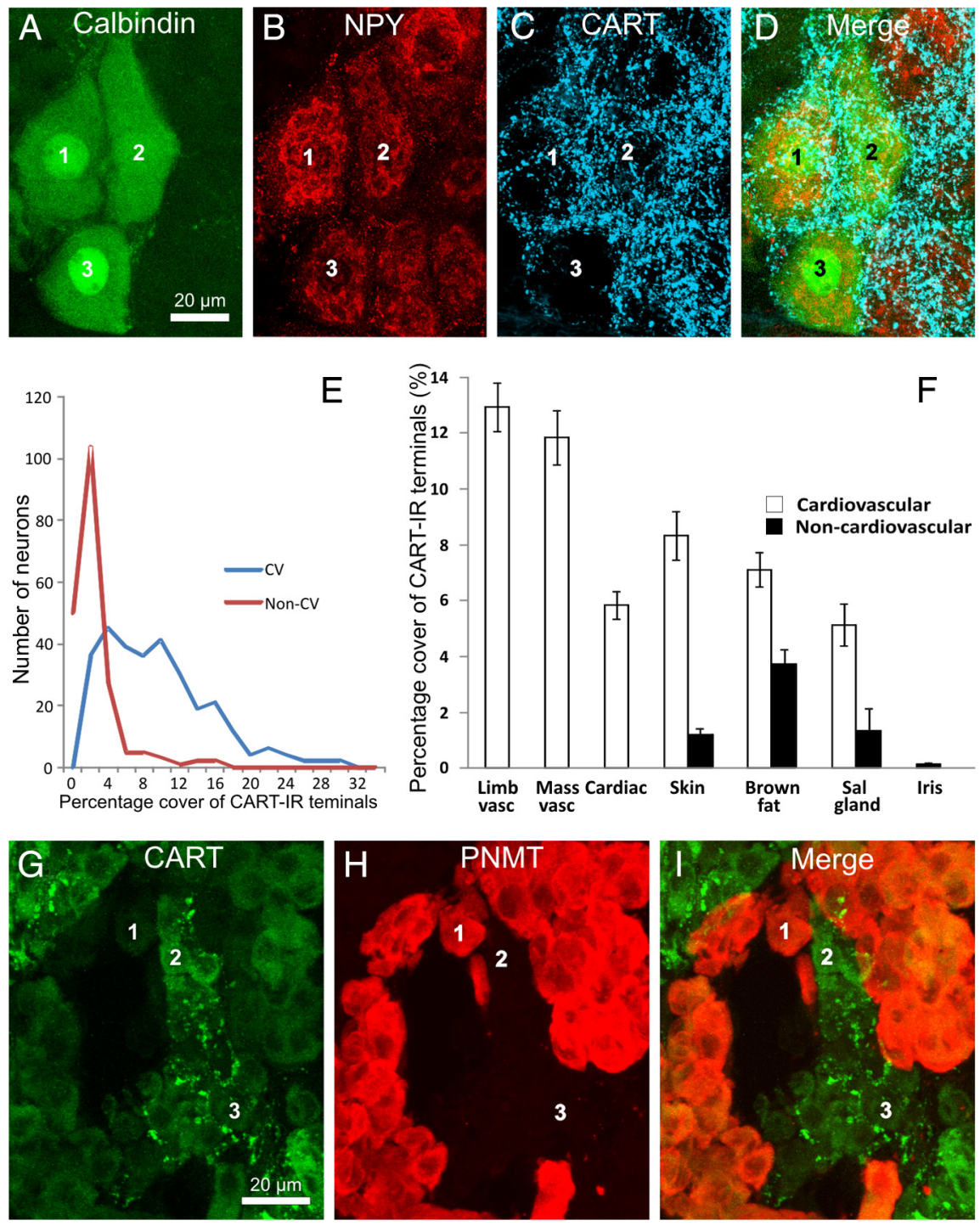

Figure 2. All images are projected $z$-series of confocal images. $\boldsymbol{A}-\boldsymbol{D}$, Stellate ganglion section showing cardiac-projecting postganglionic neurons (labeled 1-3), identified by their immunoreactivity to calbindin (A) and NPY (B) and by their location in clusters on the medial edge of the ganglion. All three cells are surrounded by dense arrays of CART-immunoreactive terminals $(\boldsymbol{C})$ $\boldsymbol{E}$, Frequency distribution of the innervation scores of all cardiovascular (blue line, CV) and non-cardiovascular (red line, Non-CV) neurons analyzed. The pooled cardiovascular neurons have strikingly higher range of innervation scores. $\boldsymbol{F}$, Analysis of the innervation scores of CART-IR terminals surrounding functionally identified postganglionic neurons in the rat SCG and stellate ganglion. The area of CART-IR terminals surrounding each cell is shown. Neurons were retrogradely labeled from the forelimb muscle (Limb vasc), masseter muscle (Mass vasc), forelimb skin (Skin), interscapular brown fat (Brown fat), submandibular salivary gland (Sal gland), and anterior eye chamber (Iris). Retrogradely labeled neurons were identified by a combination of projection and immunoreactivity to NPY. Neurons projecting to the heart (Cardiac) were identified by a combination of topography and chemistry. CART-IR terminals are clearly associated with cardiovascular postganglionic neurons (white bars) but not non-cardiovascular neurons (black bars). Non-cardiovascular neurons in the skin, brown fat, and salivary gland represent pilomotor, thermogenic, and secretomotor neurons, respectively. Error bars are \pm SEM. G-I, Rat adrenal gland, stained for CART immunoreactivity (G), PNMT immunoreactivity $(\boldsymbol{H})$, and an overlay of the two images $(\boldsymbol{I})$. Note that noradrenergic chromaffin cells lacking PNMT immunoreactivity are associated with CART-immunoreactive terminals in $\mathbf{G}$. The same cells are labeled 1-3 in each series of image.

\section{Adrenal preganglionic neurons}

We next examined whether the CART-IR preganglionic neurons that have been found previously to project to the adrenal medulla (Fenwick et al., 2006) showed any target selectivity among chromaffin cells. A potential confound to this analysis is that some chromaffin cells themselves contain CART immunoreactivity, as reported previously (Dun et al., 2000): when sections were costained for immunoreactivity to phenylethanolamine- $n$ methyl transferase (PNMT), which labels adrenergic chromaffin

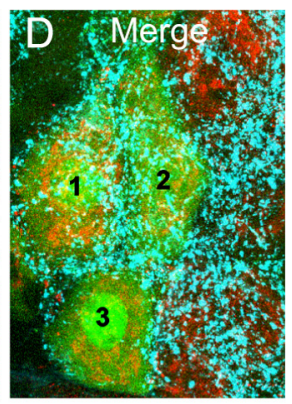

$\mathrm{F}$

cells, CART-IR cells were found to be a subset of those lacking PNMT immunoreactivity (i.e., noradrenergic chromaffin cells). CART-IR nerve fibers clearly surrounded the few clusters of noradrenergic chromaffin cells that lacked CART immunoreactivity and avoided PNMT-IR (adrenergic) chromaffin cells (Fig. 2G-I). To ascertain whether CART-IR terminals also surrounded noradrenergic chromaffin cells that themselves expressed CART immunoreactivity required confocal microscopy and costaining of sections with synaptophysin immunoreactivity to label terminal boutons. This analysis identified nerve terminals double labeled for synaptophysin and CART immunoreactivity among the CART-IR chromaffin cells, confirming that CART-IR preganglionic terminals selectively surround noradrenergic chromaffin cells, whether or not those cells themselves express CART immunoreactivity.

\section{Do all preganglionic vasoconstrictor neurons contain CART}

immunoreactivity?

The evidence presented above indicates that cardiovascular postganglionic neurons are selectively targeted by CART-IR preganglionic neurons but does not tell us whether CART-IR preganglionic neurons provide their only input. To investigate this question, we used confocal microscopy to analyze appositions of individual synaptophysin-IR boutons, with and without CART immunoreactivity, on the somata of functionally identified postganglionic neurons.

Individual postganglionic neurons that were retrogradely labeled with Fast Blue and processed for NPY immunoreactivity were analyzed in single confocal image planes from confocal $z$-series through the neurons (Fig. $3 A-D$ ). Individual boutons that appeared to contact the surface of the cell were assessed for immunoreactivity to CART and synaptophysin.

Five functionally distinct populations of neurons were examined: three vasoconstrictor (forelimb muscle, facial skin, and salivary gland vasoconstrictor) and two non-vasoconstrictor (salivary secretomotor and pilomotor). A total of 1812 boutons were examined, from five cells from each of three animals for each functional class of neuron (Table 2).

Virtually no CART-IR boutons were present in contact with the surface of identified non-vascular neurons. All varicosities in contact with secretomotor neurons displayed synaptophysin immunoreactivity only, whereas for pilomotor neurons, $98.6 \%$ of varicosities were immunoreactive for synaptophysin only.

In contrast, CART immunoreactivity was observed in a large proportion of the boutons examined around all types of vasocon- 

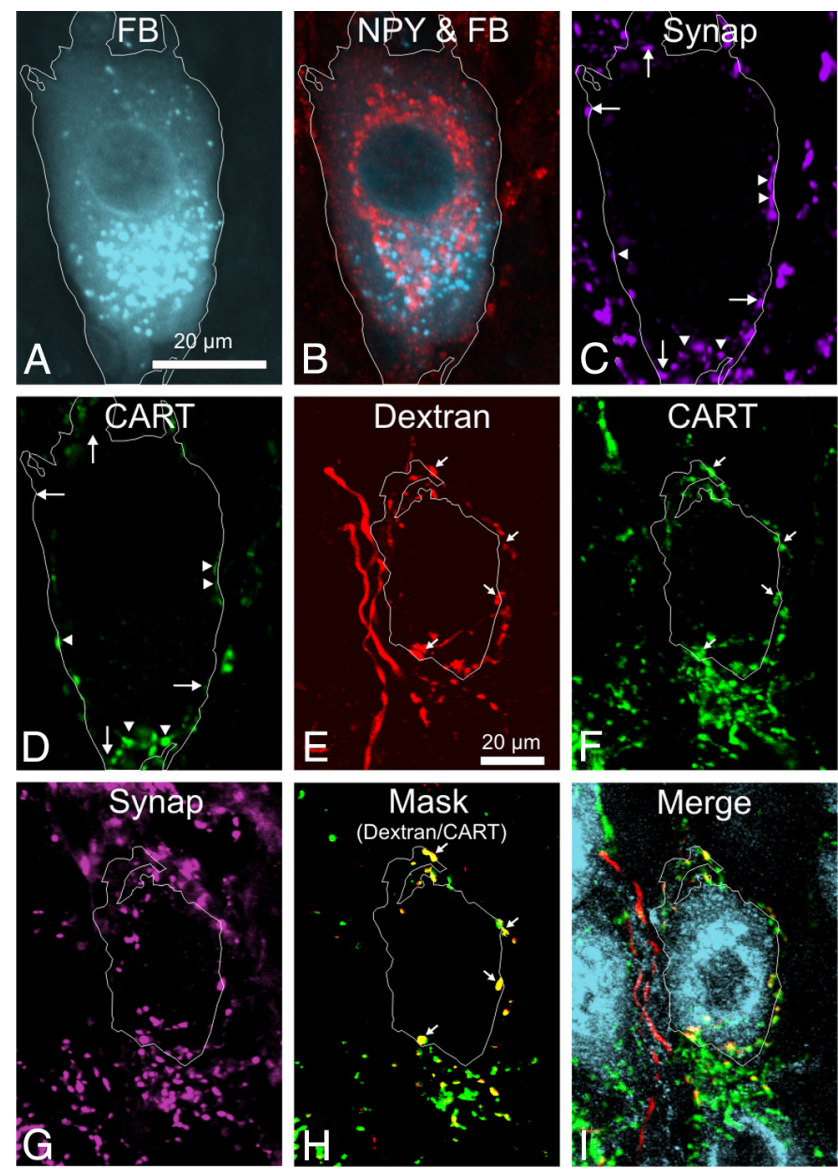

Figure 3. $A-D, A$ single image plane from a $z$-series through a sympathetic vascular postganglionic neuron in the rat stellate ganglion that has been labeled with Fast Blue injected into the brown fat $(\boldsymbol{A})$, NPY $(\boldsymbol{B})$, synaptophysin $(\boldsymbol{C})$, and CART $(\boldsymbol{D})$. The cell boundary has been outlined, based on the Fast Blue (FB) image, and shows that the cell body is in close contact with boutons immunoreactive for CART and synaptophysin (arrowheads) and for synaptophysin alone (arrows). $\boldsymbol{E}$-I, Confocal z-series of a dextran-labeled preganglionic fiber (E), also expressing CART immunoreactivity ( $\boldsymbol{F}$, arrows), surrounding a single NPY-IR neuron in the rat stellate ganglion $(\boldsymbol{I})$. The distribution of synaptophysin immunoreactivity $(\boldsymbol{G})$ was used to create a mask to allow comparison of only dextran and CART boutons that expressed synaptophysin, seen overlaid in $\boldsymbol{H}$ to show the overlap of dextran (red) and CART (green) as yellow boutons (arrows). In I, NPY, CART, and dextran are shown simultaneously without masking. Note that, in this example, a projected $z$-series has been used for clarity. The analysis reported in Results was performed on single optical sections.

strictor neurons examined: 80,61 , and $79 \%$, respectively, for forelimb muscle, salivary gland, and skin vasoconstrictor neurons (Table 2). The majority of the CART-IR boutons also contained synaptophysin immunoreactivity, but a proportion contained CART immunoreactivity only (see Table 2). Also present were boutons that contained only synaptophysin. A $\chi^{2}$ test ( $\chi^{2}$ value of 900.9 , critical value of $9.488, p \ll 0.05$, df $=4$ ) indicated that the proportion of the total number of boutons that were CART-IR contacting each class of cell was not identical. A post hoc analysis comparing multiple proportions (Zar, 1984) revealed that the proportions of CART-IR boutons (Table 2) were significantly different from each other $(p<0.05)$, except for skin and forelimb vasoconstrictor neurons, which were significantly different from all other classes but not from each other.

\section{Is CART immunoreactivity absent from some axon boutons} of CART-IR preganglionic neurons?

The presence of synaptophysin boutons both with and without CART immunoreactivity raised the possibility that there may be two different types of input to vasoconstrictor postganglionic neurons. Alternatively, both types of bouton may exist among the terminals of a single type of preganglionic neuron. To distinguish between these two possibilities, we used biotinylated dextran to label SPN terminals anterogradely (Asamoto et al., 1997).

After injecting dextran into the T4 segment of the spinal cord, labeled terminals were observed in the SCG, stellate ganglia, and thoracic ganglia (Fig. $3 E-I$ ). Relatively few preganglionic axons were labeled by each injection. This had two consequences. On the negative side, the probability of an anterogradely labeled preganglionic neuron contacting one of the neurons retrogradely labeled with Fast Blue was exceedingly low: vasoconstrictor ganglion cells were therefore identified for this analysis purely by their NPY immunoreactivity. On the positive side, individual dextran-labeled fibers could often be identified in the intraganglionic connectives and traced into ganglia, in which they branched widely and terminated in restricted patches (Asamoto et al., 1997). Sometimes all the boutons around a single postganglionic neuron could be traced back to a single fiber. On other occasions, dextran-labeled terminals gave rise to many hundreds of boutons, both with and without CART immunoreactivity, surrounding clusters of NPY-IR postganglionic neurons. In those cases, the innervation could have come from multiple preganglionic neurons.

With confocal microscopy, it was possible to determine the chemistry of individual boutons. The contacts between dextran-labeled boutons derived from a single fiber and NPY-IR postganglionic neurons were analyzed in the stellate (most cases) and superior cervical ganglion: the findings were equivalent. Two types of dextran-labeled fiber surrounding NPY-IR neurons were observed: one type lacked CART immunoreactivity in any of its boutons, whereas the other had colocalized CART immunoreactivity.

Detailed analysis was made on 32 NPY-IR neurons selected because they were surrounded by only a sparse network of CART-IR dextran-labeled fibers around the soma, presumably from a single preganglionic neuron (Fig. $3 E-I$ ). A total of 186 synaptophysin-containing, dextran-labeled boutons that were apparently in contact with the somatic surface of those 32 neurons were analyzed for the presence or absence of CART immunoreactivity. In 28 of 32 cells, CART was present in every cell-contacting, dextran-labeled bouton. Eight of the 43 boutons contacting the remaining four cells $(4.3 \%$ of the total 186 boutons) lacked CART immunoreactivity. These findings indicate that, if a preganglionic neuron expresses CART immunoreactivity, it does so in nearly all of its terminal boutons; if it lacks CART immunoreactivity, this also applies to all axon terminals.

It therefore seems clear that the $20-40 \%$ of boutons contacting the surface of vasomotor neurons that lacked CART (Table 2) were not just CART-negative boutons from otherwise CARTpositive cells. We conclude from this that NPY-IR neurons, such as all three types of vasoconstrictor neuron we examined, get inputs from two chemical classes of preganglionic neuron, one with CART immunoreactivity and one without.

\section{Distribution of CART-IR preganglionic neurons}

As reported previously (Fenwick et al., 2006), choline acetyltransferase-IR SPNs in multiple spinal cord segments were immunoreactive for CART (Fig. $4 A-C$ ). Fluorogold injected intraperitoneally retrogradely labels all SPNs (Anderson and Edwards, 1994) and allowed the numbers of CART-IR SPNs to be counted in each segment between C 8 and L2 and their rostrocaudal distribution to be determined (Fig. 5A). CART-immuno- 
Table 2. Analysis of boutons in contact with identified postganglionic neurons in the rat

\begin{tabular}{|c|c|c|c|c|c|}
\hline & Forelimb vasoconstrictor & Salivary gland vasoconstrictor & Skin vasoconstrictor & Secretomotor & Pilomotor \\
\hline CART only & $29.6 \%$ & $16.3 \%$ & $29.3 \%$ & $0 \%$ & $0.7 \%$ \\
\hline Synaptophysin only & $19.8 \%$ & $38.8 \%$ & $20.6 \%$ & $100 \%$ & $98.6 \%$ \\
\hline Colocalized & $57.1 \%$ & $44.9 \%$ & $50.1 \%$ & $0 \%$ & $0.7 \%$ \\
\hline Total CART \% & $86.7 \%$ & $61.2 \%$ & $79.4 \%$ & $0 \%$ & $1.4 \%$ \\
\hline Range \% & $56.5-100 \%$ & $17.6-92.3 \%$ & $55.6-100 \%$ & $0-0 \%$ & $0-8.3 \%$ \\
\hline Total boutons & 415 & 325 & 403 & 384 & 285 \\
\hline Total neurons/animals & $15 / 3$ & $15 / 3$ & $15 / 3$ & $15 / 3$ & $15 / 3$ \\
\hline
\end{tabular}
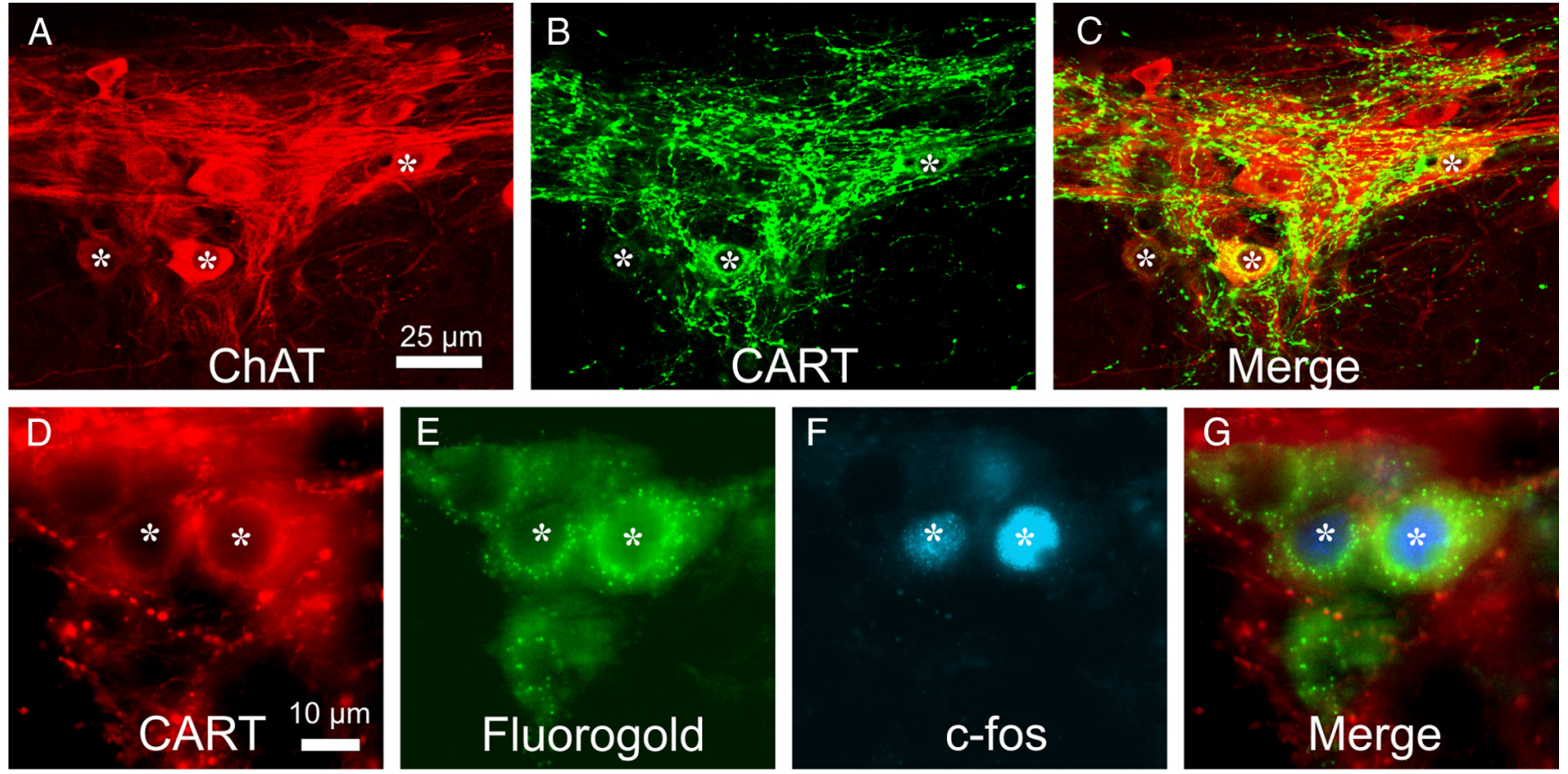

Figure 4. $A-C$, Images are projected $z$-series of confocal images; lateral is to the top of the image in each case. Horizontal sections through the intermediolateral nucleus of T3 rat spinal cord, stained for choline acetyltransferase (ChAT) immunoreactivity $(\boldsymbol{A})$, CART immunoreactivity $(\boldsymbol{B})$, and an overlay of the two images $(\boldsymbol{C})$. At least three of the ChAT-immunoreactive neurons in the intermediolateral column (asterisks) are also immunoreactive for CART. D-G, Fluorescence micrographs of horizontal sections through the intermediolateral nucleus of rat T5 spinal cord (lateral to the top), showing CART-immunoreactive neurons (D) identified as preganglionic by the presence of retrogradely transported Fluorogold $(\boldsymbol{E})$. Two of the preganglionic neurons are immunoreactive for c-Fos after a period of hypoxia $(\boldsymbol{F})$. $\boldsymbol{G}$ shows a merge of all images, and the asterisks identify the same preganglionic neurons in each image.

reactive neurons were very rare in $\mathrm{C} 8$ and $\mathrm{T} 1$, and their numbers peaked in $\mathrm{T} 5$ and again in T12. One striking feature of the distribution of CART-IR preganglionic neurons relative to those that lacked CART immunoreactivity is that the former appeared more common medially in the nucleus intermediolateralis (IML). This could be because there are differences in position between neurons projecting to different ganglia (Pyner and Coote, 1994) or because neurons projecting to a single ganglion are distributed differently according to their function.

We distinguished between the two possibilities by examining the distribution of CART-IR neurons projecting to a single sympathetic ganglion, the SCG. Fast Blue injected into the SCG labeled neurons in spinal cord segments $\mathrm{C} 8$ to $\mathrm{T} 6$, and the proportion of CART-IR SPNs in three animals was calculated in segments $\mathrm{T} 1-\mathrm{T} 5$, in which the most retrogradely labeled cells were found. Approximately one-third of all Fast Blue-labeled SPNs were immunoreactive for CART (Table 3 ), which contrasts to the $73 \%$ of SPNs that contained CART immunoreactivity after injections of virus into skeletal muscle, confirming the specific association of CART-IR SPNs with vascular pathways. CART-IR preganglionic neurons projecting to the SCG relative to those that lacked CART immunoreactivity were significantly more common medially in the IML (Kolmogorov-Smirnov goodness- of-fit test, $p<0.05$, two tailed) (Fig. 6) but did not extend across the nucleus intercalatus into the central autonomic nucleus around the central canal.

\section{Can CART-IR preganglionic neurons be activated by}

physiological stimuli?

We next wanted to examine hypoxia as a possible stimulus for inducing expression of the immediate early gene c-fos in CART-IR preganglionic neurons. Fenwick et al. (2006) have demonstrated previously that baroreceptor unloading activates only $41 \%$ of CART-immunoreactive preganglionic neurons, and we were interested in the extent to which CART-IR neurons would respond to a stimulus of arterial chemoreceptors. Exposure of rats to hypoxia induced expression of the early immediate gene c-fos in SPNs that had been prelabeled with intraperitoneally delivered Fluorogold (Fig. 4D-G). Preganglionic neurons expressing c-Fos were absent in $\mathrm{C} 8$ and $\mathrm{T} 1$ and rare in $\mathrm{L} 1$ and $\mathrm{L} 2$ (Fig. 5 B). Approximately $69 \%$ of all SPNs expressing c-Fos also expressed CART immunoreactivity. Of the total CART-IR preganglionic neurons, 33\% expressed c-Fos. The distribution of preganglionic neurons with CART and c-Fos was similar to that of CART alone (very rare in neurons in $\mathrm{C} 8$ and $\mathrm{T} 1$ and peaking in T4 and T13, with a nadir at T9) (Fig. 5A). The one exception was 

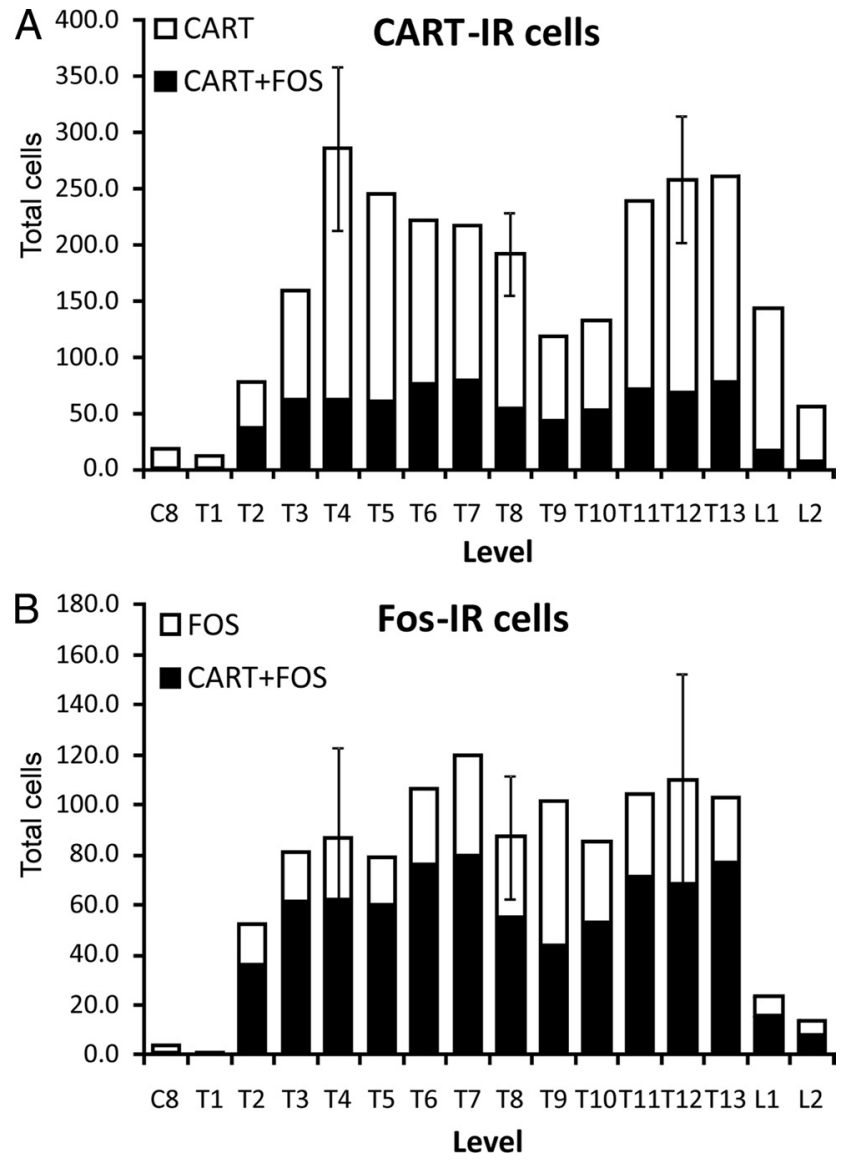

Figure 5. A, Distribution of CART-IR sympathetic preganglionic neurons in the spinal cord of the rat. Also shown (blacks bars) are the proportion of the total CART-IR sympathetic preganglionic neurons in each segment that were $c$-Fos-immunoreactive after hypoxia. $\boldsymbol{B}$, Distribution of the c-Fos-immunoreactive sympathetic preganglionic neurons in the spinal cord of the rat. The black bars are the proportion of c-Fos-immunoreactive preganglionic neurons that also contain CART. Both $\boldsymbol{A}$ and $\boldsymbol{B}$ are the means of two animals except for segments T4, T8, and T12, which are the means of three animals. Error bars are SEM.

Table 3. CART immunoreactivity in SCG-projecting sympathetic preganglionic neurons

\begin{tabular}{lllllll}
\hline & $\mathrm{T} 1$ & $\mathrm{~T} 2$ & $\mathrm{~T} 3$ & $\mathrm{~T} 4$ & $\mathrm{~T} 5$ & Total \\
\hline Total Fast Blue cells & 484 & 1144 & 898 & 684 & 157 & 3367 \\
CART-IR cells & 141 & 352 & 333 & 222 & 66 & 1114 \\
\% of total Fast Blue cells in segment & $(29 \%)$ & $(31 \%)$ & $(49 \%)$ & $(32 \%)$ & $(42 \%)$ & $(33 \%)$ \\
\hline
\end{tabular}

that, compared with the thoracic spinal cord, c-Fos expression after hypoxia was relatively rare in CART-IR neurons in L1-L2. Among c-Fos-IR neurons, a broadly similar proportion expressed CART at each segmental level between T2 and L2.

\section{Discussion}

Dun et al. (2000) first showed that CART immunoreactivity was present in rat SPN. This was confirmed by Fenwick et al. (2006), who showed that these neurons project to the adrenal gland and to a range of sympathetic ganglia. The current study extends those observations by providing clear evidence that CART-IR preganglionic neurons selectively target vasoconstrictor and cardiac postganglionic neurons in the SCG and stellate ganglia as well as the noradrenergic chromaffin cells of the adrenal medulla ("cardiovascular" sympathetic neurons). Additionally, this study shows that the cardiovascular postganglionic neurons receive in-

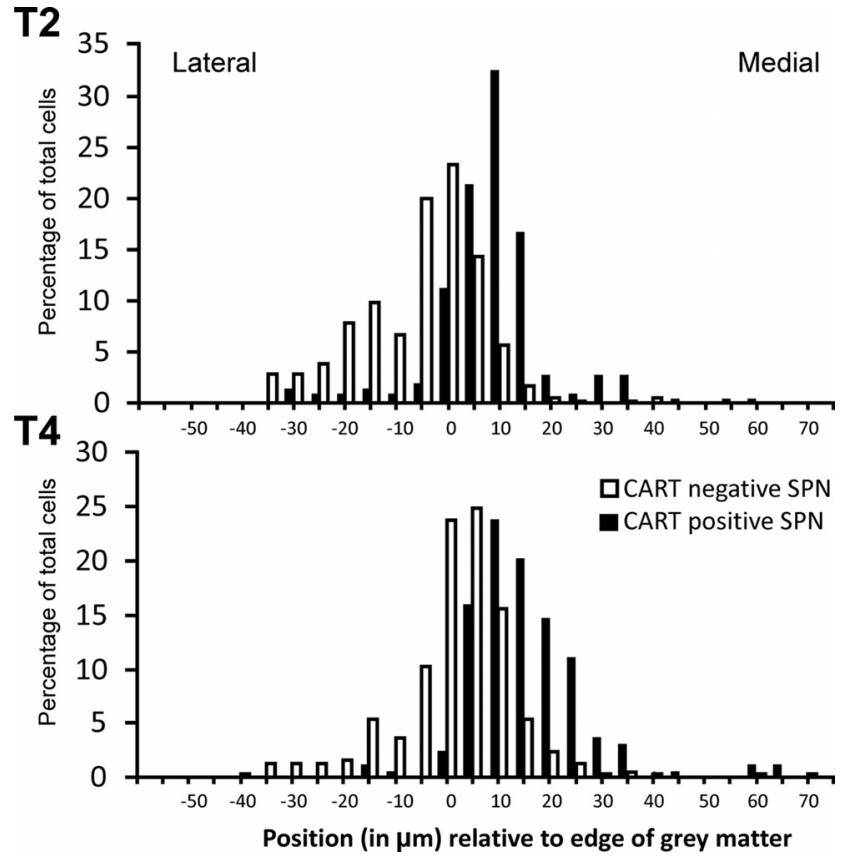

Figure 6. Frequency plot of the mediolateral position of sympathetic preganglionic neurons in the intermediolateral column of $\mathrm{T} 2$ and $\mathrm{T} 4 \mathrm{segments}$ of rat spinal cord. Preganglionic neurons immunoreactive for CART tend to be located more medially than preganglionic neurons that lack CART immunoreactivity.

puts from SPNs both with and without CART immunoreactivity. Finally, 69\% of the preganglionic neurons expressing c-Fos after the animal was subjected to hypoxia also expressed CART immunoreactivity, indicating that hypoxia is a strong stimulus of CART-IR preganglionic neurons. The implications of these findings are considered below.

\section{CART immunoreactivity as a marker of cardiovascular} neurons

All data from the present study are compatible with the view that CART immunoreactivity selectively identifies cardiovascular preganglionic neurons and is expressed by a substantial subset (but not all) of that population. Within the stellate ganglion and SCG, CART-IR terminals almost exclusively surround the cell bodies of NPY-IR vasoconstrictor and cardiac neurons but they avoid non-vasoconstrictor neurons, including the NPY-IR neurons that innervate the iris. Furthermore, identified vasoconstrictor neurons, but not non-cardiovascular neurons, have CART-IR boutons directly apposed to their surface. Finally, transneuronal retrograde labeling with pseudorabies virus confirms that CART-IR SPNs are indeed disynaptically connected to blood vessels.

In the adrenal gland, CART-IR terminals are present and are only associated with noradrenergic chromaffin cells, which make up 19\% of chromaffin cells in the adult rat adrenal medulla (Murphy et al., 2000 ). The $14 \%$ of retrogradely labeled preganglionic neurons innervating the adrenal medulla that contain CART immunoreactivity (Fenwick et al., 2006) therefore represents a preganglionic supply to exclusively noradrenergic chromaffin cells, confirming that the rat, like the cat (Edwards et al., 1996), has distinct chemical types of preganglionic neuron innervating adrenergic and noradrenergic chromaffin cells. In the rat, preganglionic neurons innervating adrenergic chromaffin cells express enkephalin (Pelto-Huikko et al., 1985; Henion and Landis, 1990; Holgert et al., 1995), whereas those innervating noradrenergic 


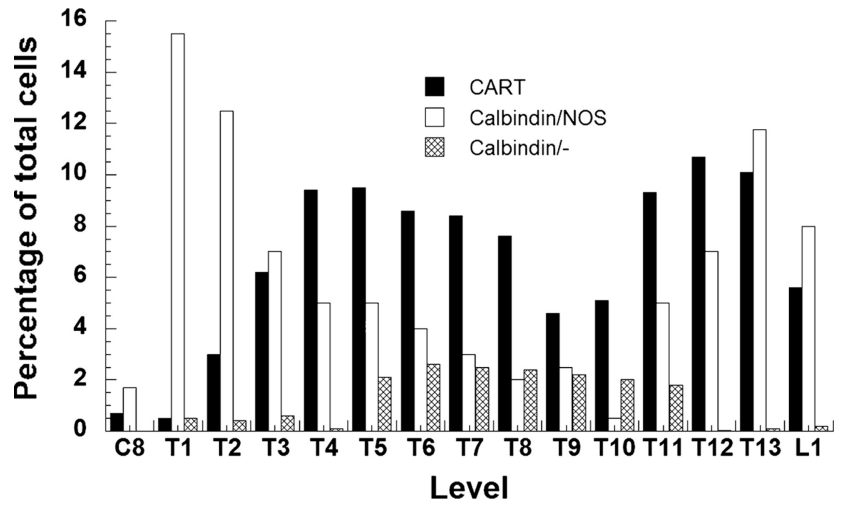

Figure 7. The segmental distribution of CART-IR sympathetic preganglionic neurons from this study compared with the distribution of sympathetic preganglionic neurons immunoreactive for calbindin and NOS or calbindin alone (additional data from Grkovic and Anderson, 1997).

chromaffin cells do not. Because all SPNs innervating the rat adrenal medulla express nitric oxide synthase (NOS) (Afework and Burnstock, 1995; Holgert et al., 1995; Schäfer et al., 1998), this substance must be occur with CART immunoreactivity in neurons innervating noradrenergic chromaffin cells. Importantly, it is the SPN supplying noradrenergic chromaffin cells that are barosensitive and behave functionally as cardiovascular neurons (Cao and Morrison, 2000, 2001).

\section{Distribution of CART-IR neurons}

CART-IR sympathetic preganglionic neurons have a distinctive rostrocaudal distribution in the thoracolumbar spinal cord. They were essentially absent from C8 and T1, but their numbers peaked in the midthoracic region and again in T13-L1, with a nadir at T9. They also had a quite specific distribution mediolaterally within the IML, being most common medially in the IML and very rare in the white matter lateral to the IML (the nucleus intermediolateralis, pars funicularis) (Petras and Cummings, 1972). The medial location of CART-IR neurons was also seen when only SPNs projecting to a single ganglion, the SCG, were considered. Previously, retrograde-labeling studies have identified distinct longitudinal columns of preganglionic neurons within the IML, each of which projects to a specific ganglion or to the adrenal medulla (Baron et al., 1985a,b,c; Jänig and McLachlan, 1986a,b; Pyner and Coote, 1994). Our study has shown that these columns can be further subdivided mediolaterally on the basis of neuronal phenotype (and, by inference, function).

Overall, we have relatively few examples of the distribution of distinct subsets of SPNs in the rat spinal cord. Grkovic et al. (1997) reported the rostrocaudal distribution of preganglionic neurons immunoreactive for either calbindin alone or calbindin coexpressed with NOS. Both had distributions that were unique and different from that of CART-IR preganglionic neurons (Fig. 7).

The absence of CART-IR neurons from C8 and T1 segments (Fenwick et al., 2006; this study) is consistent with their proposed cardiovascular function. Langley (1900) and Njå and Purves (1977a,b) showed in mammals that stimulation of the C8 and T1 ventral roots activated postganglionic neurons controlling the iris, but no vasoconstriction of the ear was seen until the T2 and more caudal ventral roots were stimulated.

\section{Comparison with previous work}

The present findings that CART immunoreactivity selectively labels cardiovascular SPN differs from the conclusion reached by a previous study (Fenwick et al., 2006), that CART immunoreactivity in rat SPNs cuts across functional classes. That conclusion was reached on the basis of two findings: (1) only a minority of the SPNs that expressed c-Fos after a hypotensive stimulus (putative cardiovascular SPNs) were found to contain CART immunoreactivity, whereas CART immunoreactivity was present in many SPNs without c-Fos; (2) CART-IR SPNs projected to a range of sympathetic ganglia, including those (e.g., the main pelvic ganglion) in which few vasoconstrictor neurons are likely to reside (Fenwick et al., 2006). Our data do not address this last point and do not exclude the possibility that CART immunoreactivity labels some lumbar SPNs with "non-cardiovascular" functions, in addition to cardiovascular SPNs.

With regard to the first argument above, hypotension is a rather weak stimulus for c-Fos expression in SPNs; indeed, some workers have failed to detect c-Fos expression in SPNs even after hypotensive stimuli that evoked strong c-Fos expression in cells of the rostral ventrolateral medulla (McAllen et al., 1992; Badoer et al., 1993). The SPNs that have been found to express c-Fos after hypotensive stimuli appear to be a select group-mainly adrenalprojecting neurons of the lower thoracic cord (Minson et al., 1996, 2002)—rather than all cardiovascular SPNs. The reasons for this are unclear, but it means that one should not be surprised to find that only a minority of cardiovascular SPNs express c-Fos after hypotension. Nor should one be surprised to find that many CART-IR-negative SPNs express c-Fos after hypotension, even if this is a selective stimulus for cardiovascular neurons, because $20-30 \%$ of cardiovascular SPNs lack CART immunoreactivity (this study). The observations of Fenwick et al. (2006) therefore do not refute the view that CART-IR SPNs of the rat's thoracic cord are cardiovascular.

\section{Functional correlates of CART-immunoreactive preganglionic neurons}

The present findings indicate clearly that most cardiovascular SPNs express CART immunoreactivity, but a clear minority ( $\sim 20-30 \%$ ) do not. The two populations converge to supply the same ganglion cells. On the basis that in both preganglionic and postganglionic sympathetic neurons chemical phenotype is tightly linked to function, we hypothesize that these two neuronal populations play distinct functional roles. What might those distinct roles be?

It has been argued previously, on the basis of physiological experiments, that two functional classes of SPNs innervate vasomotor postganglionic neurons (Jänig et al., 1983; Jänig, 2005; McAllen et al., 2005): these have been termed "regular" and "accessory" (McAllen et al., 2005). The regular pathway provides resting tone, is strongly activated by baroreceptor unloading, and communicates with ganglion cells by conventional nicotinic transmission (Henderson and Ungar, 1978; Jänig, 1995). In contrast, the accessory preganglionic pathway may not drive much basal tone, but it is strongly stimulated by arterial chemoreceptors and can activate vasoconstrictor pathways by non-nicotinic transmission (Henderson and Ungar, 1978; Jänig et al., 1983, 1984). Physiologically, when nicotinic transmission is intact, non-nicotinic actions are likely to provide excitatory modulation rather than direct drive. It is therefore relevant that a recent intracellular study of synaptic processing by vasomotor ganglion cells in vivo has found that the gain of transmission from preganglionic to postganglionic action potentials is sensitive to small changes in ganglion cell excitability, as may be caused by peptides (Bratton et al., 2010). 
The present findings may have provided the anatomical substrate for this dual control of cardiovascular postganglionic neurons. If so, the preferential activation of CART-IR SPNs by hypoxia (this study) compared with hypotension (Fenwick et al., 2006) implicates CART-IR cells as the accessory SPN (and of course suggests CART as a candidate peptide transmitter).

\section{References}

Afework M, Burnstock G (1995) Colocalization of neuropeptides and NADPH-diaphorase in the intra-adrenal neuronal cell bodies and fibres of the rat. Cell Tissue Res 280:291-295.

Anderson CR, Edwards SL (1994) Intraperitoneal injections of Fluorogold reliably label all sympathetic preganglionic neurons in the rat. J Neurosci Methods 53:137-141.

Anderson CR, Howe PR (1988) Is phenylethanolamine- $N$-methyl-transferase contained in rat hypothalamic neurons? Neurosci Lett 93:164-169.

Asamoto K, Tamamaki N, Nojyo Y (1997) Arborization pattern of sympathetic preganglionic axons in the rat superior cervical and stellate ganglia. Neurosci Res 28:235-241.

Bachoo M, Ciriello J, Polosa C (1987) Effects of preganglionic stimulation on neuropeptide-like immunoreactivity in the stellate ganglion of the cat. Brain Res 400:377-382.

Badoer E, McKinley MJ, Oldfield BJ, McAllen RM (1993) A comparison of hypotensive and non-hypotensive hemorrhage on Fos expression in spinally projecting neurons of the paraventricular nucleus and rostral ventrolateral medulla. Brain Res 610:216-223.

Baron R, Jänig W, McLachlan EM (1985a) The afferent and sympathetic components of the lumbar outflow to the colon and pelvic organs in the cat. I. The hypogastric nerve. J Comp Neurol 238:135-146.

Baron R, Jänig W, McLachlan EM (1985b) The afferent and sympathetic components of the lumbar outflow to the colon and pelvic organs in the cat. II. The lumbar splanchnic nerves. J Comp Neurol 238:147-157.

Baron R, Janig W, McLachlan EM (1985c) The afferent and sympathetic components of the lumbar outflow to the colon and pelvic organs in the cat. III. The colonic nerves, incorporating an analysis of all components of the lumbar prevertebral outflow. J Comp Neurol 238:158-168.

Benarroch EE (1994) Neuropeptides in the sympathetic system: presence, plasticity, modulation, and implications. Ann Neurol 36:6-13.

Billig I, Foris JM, Enquist LW, Card JP, Yates BJ (2000) Definition of neuronal circuitry controlling the activity of phrenic and abdominal motoneurons in the ferret using recombinant strains of pseudorabies virus. J Neurosci 20:7446-7454.

Blessing WW, Howe PR, Joh TH, Oliver JR, Willoughby JO (1986) Distribution of tyrosine hydroxylase and Neuropeptide Y-like immunoreactive neurons in rabbit medulla oblongata, with attention to colocalisation studies, presumptive adrenaline-synthesizing perikarya, and vagal preganglionic cells. J Comp Neurol 248:285-300.

Blumberg H, Jänig W (1983) Enhancement of resting activity in postganglionic vasoconstrictor neurones following short-lasting repetitive activation of preganglionic axons. Pflugers Arch 396:89-94.

Bratton B, Davies P, Jänig W, McAllen R (2010) Ganglionic transmission in a vasomotor pathway studied in vivo. J Physiol 588:1647-1659.

Cane KN, Anderson CR (2009) Generating diversity: Mechanisms regulating the differentiation of autonomic neuron phenotypes. Auton Neurosci 151:17-29.

Cannon B, Nedergaard J, Lundberg JM, Hökfelt T, Terenius L, Goldstein M (1986) Neuropeptide Tyrosine (NPY) is stored in vascular but not in parenchymal sympathetic nerves of brown adipose tissue. Exp Cell Res 164:546-550.

Cao WH, Morrison SF (2000) Responses of adrenal sympathetic preganglionic neurons to stimulation of cardiopulmonary receptors. Brain Res $887: 46-52$

Cao WH, Morrison SF (2001) Differential chemoreceptor reflex responses of adrenal preganglionic neurons. Am J Physiol Regul Integr Comp Physiol 281:R1825-R1832.

Corcoran JP, So PL, Maden M (2004) Disruption of the retinoid signalling pathway causes a deposition of amyloid beta in the adult rat brain. Eur J Neurosci 20:896-902.

Dun NJ, Dun SL, Kwok EH, Yang J, Chang J (2000) Cocaine- and amphetamine-regulated transcript immunoreactivity in the rat sympathoadrenal axis. Neurosci Lett 283:97-100.

Edvinsson L, Copeland JR, Emson PC, McCulloch J, Uddman R (1987)
Nerve fibers containing neuropeptide $\mathrm{Y}$ in the cerebrovascular bed: immunocytochemistry, radioimmunoassay, and vasomotor effects. J Cereb Blood Flow Metab 7:45-57.

Edwards SL, Anderson CR, Southwell BR, McAllen RM (1996) Distinct preganglionic neurons innervate noradrenaline and adrenaline cells in the cat adrenal medulla. Neuroscience 70:825-832.

Ekström J, Ekman R, Luts A, Sundler F, Tobin G (1996) Neuropeptide Y in salivary glands of the rat: origin, release and secretory effects. Regul Pept 61:125-134.

Fenwick NM, Martin CL, Llewellyn-Smith IJ (2006) Immunoreactivity for cocaine- and amphetamine-regulated transcript in rat sympathetic preganglionic neurons projecting to sympathetic ganglia and the adrenal medulla. J Comp Neurol 495:422-433.

Furness JB (2006) The enteric nervous system. London: Blackwell Livingstone.

Gibbins IL (1995) Chemical neuroanatomy of sympathetic ganglia. In: Autonomic ganglia (McLachlan EM, ed), pp 73-122. Luxembourg: Harwood Academic Publishers.

Grkovic I, Anderson CR (1995) Calretinin-containing preganglionic terminals in the rat superior cervical ganglion surround neurons projecting to the submandibular gland. Brain Res 684:127-135.

Grkovic I, Anderson CR (1997) Calbindin D28K immunoreactivity identifies distinct subpopulations of sympathetic pre- and postganglionic neurons in the rat. J Comp Neurol 386:245-259.

Grkovic I, Edwards SL, Murphy SM, Anderson CR (1999) Chemically distinct preganglionic inputs to iris-projecting postganglionic neurons in the rat; a light and electron microscopic study. J Comp Neurol 412:606-616.

Häbler HJ, Jänig W, Krummel M, Peters OA (1994) Reflex patterns in postganglionic neurons supplying skin and skeletal muscle of rat hindlimb. J Neurophysiol 72:2222-2236.

Henderson CG, Ungar A (1978) Effect of cholinergic antagonists on sympathetic ganglionic transmission of vasomotor reflexes from the carotid baroreceptors and chemoreceptors of the dog. J Physiol 277:379-385.

Henion PD, Landis SC (1990) Asynchronous appearance and topographic segregation of neuropeptide-containing cells in the developing rat adrenal medulla. J Neurosci 10:2886-2896.

Holgert H, Aman K, Cozzari C, Hartman BK, Brimijoin S, Emson P, Goldstein M, Hökfelt T (1995) The cholinergic innervation of the adrenal gland and its relation to enkephalin and nitric oxide. Neuroreport 6:2576-2580

Horn AK, Eberhorn A, Härtig W, Ardeleanu P, Messoudi A, Büttner-Ennever JA (2008) Perioculomotor cell groups in monkey and man defined by their histochemical and functional properties: reappraisal of the EdingerWestphal nucleus. J Comp Neurol 507:1317-1335.

Jänig W (2005) Non-nicotinic transmission in autonomic ganglia revisited-an important physiological function? J Physiol 566:1-2.

Jänig W (2006) The integrative action of the autonomic nervous system. Cambridge: Cambridge UP.

Jänig W, McLachlan EM (1986a) The sympathetic and sensory components of the caudal lumbar sympathetic trunk in the cat. J Comp Neurol 245:62-73.

Jänig W, McLachlan EM (1986b) Identification of distinct topographical distributions of lumbar sympathetic and sensory neurons projecting to end organs with different functions in the cat. J Comp Neurol 246: $104-112$.

Jänig W, Krauspe R, Wiedersatz G (1982) Transmission of impulses from pre- to postganglionic vasoconstrictor and sudomotor neurons. J Auton Nerv Syst 6:95-106.

Jänig W, Krauspe R, Wiedersatz G (1983) Reflex activation of postganglionic vasoconstrictor neurones supplying skeletal muscle by stimulation of arterial chemoreceptors via non-nicotinic synaptic mechanisms in sympathetic ganglia. Pflugers Arch 396:95-100.

Jänig W, Krauspe R, Wiedersatz G (1984) Activation of postganglionic neurones via non-nicotinic synaptic mechanisms by stimulation of thin preganglionic axons. Pflugers Arch 401:318-320.

Jänig WM (1995) Ganglionic transmission in vivo. In: Autonomic ganglia (McLachlan EM, ed), pp 349-395. Luxembourg: Harwood Academic Publisher.

Kerman IA, Enquist LW, Watson SJ, Yates BJ (2003) Brainstem substrates of sympatho-motor circuitry identified using trans-synaptic tracing with pseudorabies virus recombinants. J Neurosci 23:4657-4666.

Kerman IA, Shabrang C, Taylor L, Akil H, Watson SJ (2006) Relationship of 
presympathetic-premotor neurons to the serotonergic transmitter system in the rat brainstem. J Comp Neurol 499:882-896.

Kim JH, Lee JA, Song YM, Park CH, Hwang SJ, Kim YS, Kaang BK, Son H (2006) Overexpression of calbindin-D28K in hippocampal progenitor cells increases neuronal differentiation and neurite outgrowth. FASEB J 20:109-111.

Knaus P, Betz H (1990) Mapping of a dominant immunogenic region of synaptophysin, a major membrane protein of synaptic vesicles. FEBS Lett 261:358-360.

Koylu EO, Couceyro PR, Lambert PD, Kuhar MJ (1998) Cocaine- and amphetamine-regulated transcript peptide immunohistochemical localization in the rat brain. J Comp Neurol 391:115-132.

Lacroix JS, Anggård A, Hökfelt T, O’Hare MM, Fahrenkrug J, Lundberg JM (1990) Neuropeptide Y: presence in sympathetic and parasympathetic innervation of the nasal mucosa. Cell Tissue Res 259:119-128.

Landis SC (1992) Cellular and molecular mechanisms determining neurotransmitter phenotypes in sympathetic neurons. In: Determination of neuronal identity (Shankland M, Macagno ER, eds), pp 497-523. San Diego: Academic.

Langley JN (1900) The sympathetic and other related systems of nerves, Pt A. In: Textbook of physiology (Schaffer EA, ed), pp 616-654. Edinburgh: Pentland.

Macrae IM, Furness JB, Costa M (1986) Distributions of subgroups of noradrenaline neurons in the coeliac ganglion of the guinea-pig. Cell Tissue Res 244:173-180.

Marc RE, Jones BW (2002) Molecular phenotyping of retinal ganglion cells. J Neurosci 22:413-427.

Markram H, Toledo-Rodriguez M, Wang Y, Gupta A, Silberberg G, Wu C (2004) Interneurons of the neocortical inhibitory system. Nat Rev Neurosci 5:793-807.

McAllen RM, Badoer E, Shafton AD, Oldfield BJ, McKinley MJ (1992) Hemorrhage induces c-fos immunoreactivity in spinally projecting neurons of cat subretrofacial nucleus. Brain Res 575:329-332.

McAllen RM, Allen AM, Bratton BO (2005) A neglected "accessory" vasomotor pathway: implications for blood pressure control. Clin Exp Pharmacol Physiol 32:473-477.

Minson J, Arnolda L, Llewellyn-Smith I, Pilowsky P, Chalmers J (1996) Altered c-fos in rostral medulla and spinal cord of spontaneously hypertensive rats. Hypertension 27:433-441.

Minson JB, Arnolda LF, Llewellyn-Smith IJ (2002) Neurochemistry of nerve fibers apposing sympathetic preganglionic neurons activated by sustained hypotension. J Comp Neurol 449:307-318.

Murphy DA, Thompson GW, Ardell JL, McCraty R, Stevenson RS, Sangalang VE, Cardinal R, Wilkinson M, Craig S, Smith FM, Kingma JG, Armour JA
(2000) The heart reinnervates after transplantation. Ann Thorac Surg 69:1769-1781.

Njå A, Purves D (1977a) Specific innervation of the guinea-pig superior cervical ganglion cells by different preganglionic fibres arising from different levels of the spinal cord. J Physiol 264:565-583.

Njå A, Purves D (1977b) Re-innervation of guinea pig superior cervical ganglion cells by preganglionic fibres arising from different levels of the spinal cord. J Physiol 272:633-651.

Pelto-Huikko M, Salminen T, Hervonen A (1985) Localisation of enkephalins in adrenaline cells and nerves innervating adrenaline cells in rat adrenal medulla. Histochemistry 82:377-383.

Pernow J, Ohlén A, Hökfelt T, Nilsson O, Lundberg JM (1987) Neuropeptide $\mathrm{Y}$ : presence in perivascular noradrenergic neurons and vasoconstrictor effects on skeletal muscle blood vessels in experimental animals and man. Regul Pept 19:313-324.

Petras JM, Cummings JF (1972) Autonomic neurons in the spinal cord of the rhesus monkey: a correlation of the findings of cytoarchitectonics and sympathectomy with fibre degeneration following dorsal rhizotomy. J Comp Neurol 146:189-218.

Pyner S, Coote JH (1994) Evidence that sympathetic preganglionic neurones are arranged in target-specific columns in the thoracic spinal cord of the rat. J Comp Neurol 342:15-22.

Richardson RJ, Grkovic I, Allen AM, Anderson CR (2006) Separate neurochemical classes of sympathetic postganglionic neurons project to the left ventricle of the rat heart. Cell Tissue Res 324:9-16.

Schäfer MK, Eiden LE, Weihe E (1998) Cholinergic neurons and terminal fields revealed by immunohistochemistry for the vesicular acetylcholine transporter. II. The peripheral nervous system. Neuroscience 84:361-376.

Schotzinger RJ, Landis SC (1990) Postnatal development of autonomic and sensory innervation of thoracic hairy skin in the rat. Cell Tissue Res 260:575-587.

Terenghi G, Polak JM, Allen JM, Zhang SQ, Unger WG, Bloom SR (1983) Neuropeptide $\mathrm{Y}$ immunoreactive nerves in the uvea of guinea pig and rat. Neurosci Lett 42:33-38.

Thim L, Kristensen P, Larsen PJ, Wulff BS (1998) CART, a new anorectic peptide. Int J Biochem Cell Biol 30:1281-1284.

Tse YC, Lai CH, Lai SK, Liu JX, Yung KK, Shum DK, Chan YS (2008) Developmental expression of NMDA and AMPA receptor subunits in vestibular nuclear neurons that encode gravity-related horizontal orientations. J Comp Neurol 508:343-364.

Wiedenmann B, Franke WW (1985) Identification and localisation of synaptophysin, an integral membrane glycoprotein of $\mathrm{Mr} 38,000$ characteristic of presynaptic vesicles. Cell 41:1017-1028.

Zar JH (1984) Biostatistical analysis, Ed 4. London: Prentice-Hall. 